\title{
Bone metabolism during methylprednisolone pulse therapy in rheumatoid arthritis
}

\author{
J W J BIJLSMA, S A DUURSMA, AND O HUBER-BRUNING
}

From the Department of Rheumatology and Clinical Research Group for Bone Metabolism, University Hospital Utrecht, Box 16250, Utrecht, The Netherlands

SUMmARY The deleterious effects of corticosteroids (CS) on bone are well known, but probably differ depending on duration and dosage of CS therapy. Presently huge amounts of CS are given over a short period of time in different rheumatic conditions. Not much is known about the effect of this kind of CS treatment on bone metabolism. Twenty patients with persistently active rheumatoid arthritis were treated with $1 \mathrm{~g}$ methylprednisolone (MP) three times on alternate days over a five day period. Twenty four hours after the first MP pulse serum calcium was increased and the values of parathyroid hormone and 1,25-dihydroxyvitamin $D$ tended to increase. After the second MP pulse, however, these values had returned to the starting values. The urinary calcium excretion increased during MP pulse therapy and returned to the initial value immediately after the pulse therapy. The hydroxyproline excretion tended to decrease during therapy and stayed decreased immediately afterwards, indicating a decrease in bone resorption. It is concluded that bone metabolism is not seriously affected during MP pulse therapy.

Key words: calcium, parathyroid hormone, 1,25-dihydroxyvitamin D, hydroxyproline excretion.

Rheumatoid arthritis (RA) is associated with a local and a generalised change in bone metabolism. The juxta-articular osteopenia, a hallmark of roentgenological changes, appears to be mediated by local inflammation. In addition, a more generalised involvement of the axial and peripheral skeleton may occur. This generalised involvement is probably related to loss of mobility ${ }^{1}$ and often, subsequent lack of sunshine. When the disease progresses the use of concomitant corticosteroid (CS) therapy enhances the development of osteopenia, and perhaps this is the most important factor in clinically relevant osteopenia in RA.

Because of the deleterious side effects of CS many rheumatologists try to refrain from CS treatment. Nevertheless, steroids do ameliorate rheumatic inflammation and they are used quite often. During a recent conference on the role of steroids in the treatment of arthritis it was noted that 'preaching differed considerably from practice' and that as

Accepted for publication 28 February 1986.

Correspondence to Dr J W J Bijlsma. Department of Rheumatology. University Hospital of Utrecht, Box 16250, 3500 CG Utrecht. The Netherlands. many as $25 \%$ of all rheumatoid patients were taking $\mathrm{CS}^{2}$

During recent years the use of methylprednisolone (MP) pulse therapy has been advocated for a variety of rheumatic diseases that are refractory to more standard treatment regimens. In RA there are two potentially useful roles for MP pulse therapy: (a) in patients with persistently active disease, who either fail to respond to conventional long term therapy, such as gold or penicillamine, or have been unable to tolerate these drugs; $(b)$ in bridging the gap between the introduction of slow acting antirheumatic drugs and the delayed response to these drugs. ${ }^{3}$ MP pulse therapy is claimed to be a safer alternative to regular systemic CS therapy. ${ }^{4}$ This study was undertaken to examine the short term effect of MP pulse therapy on bone metabolism in patients with active rheumatoid arthritis.

\section{Patients and methods}

Twenty patients, 19 women (three pre- and 16 postmenopausal) and one man, with definite RA (American Rheumatism Association criteria) and mean age 60.6 years (range 36-77 years) were 
studied. The mean duration of their disease was 14 years; all were seropositive and had erosive changes on their $x$ rays (unpublished data). In all these patients previously intensive second line treatment had not resulted in a satisfactory remission or had caused side effects. All patients had an active arthritis, and no contraindications against MP pulse therapy were found. No patient was taking steroids or any other drug that is known to influence bone metabolism; all continued their non-steroidal antiinflammatory drugs.

The patients were admitted to the hospital and they were advised to stay in bed during the first five to seven days. They received $1 \mathrm{~g}$ MP infusion over 30 minutes, three times on alternate days over a five day period. Urine was collected during $24 \mathrm{~h}$ a day, starting two days before the MP pulse therapy and continuing until three days after the last MP infusion. Fasting blood samples were drawn before the first pulse, $24 \mathrm{~h}$ after the first, $24 \mathrm{~h}$ after the second, and three days after the last MP pulse infusion. On the fourth or fifth day after the last infusion the patients were discharged from hospital. On the day of the first MP pulse they also started treatment with $50 \mathrm{mg}$ azathioprine daily; this drug does not influence bone metabolism.

The following determinations were performed: (a) calcium ( $\mathrm{Ca}$ ) in serum and urine by atomic absorption; (b) parathyroid hormone (PTH) by a radioimmunoassay that recognises the carboxyl terminal region; (c) 25-hydroxycholecalciferol $\left(25-\mathrm{OHD}_{3}\right)$ and 1,25 dihydroxycholecalciferol $\left(1 \alpha, 25\left(\mathrm{OH}_{2}\right) \mathrm{D}_{3}\right)$ by competitive protein binding assay; $(d)$ creatinine $(\mathrm{Cr})$ concentration in the urine by autoanalyser Technicon; $(e)$ hydroxyproline (OHProl) concentration in the urine by the method of Hoppe-Seyler.

The concentrations of urinary $\mathrm{Ca}, \mathrm{Cr}$, and OHProl were expressed in $\mathrm{mmol} / \mathrm{l}$ and the following ratios were calculated: $\mathrm{Ca} / \mathrm{Cr}$ and $\mathrm{OHProl}(\times 1000) /$
Cr. In our experience the normal values for these ratios are: $\mathrm{Ca} / \mathrm{Cr} \leqslant 0 \cdot 30$ and $\mathrm{OHProl} / \mathrm{Cr} \leqslant 20 .{ }^{5}$

The data obtained were analysed by means of a non-parametric test (Wilcoxon).

\section{Results}

In Table 1 the relevant data are summarised. In Figs $\overparen{\mathbb{Q}}$

1 and 2 these data are further illustrated.

Serum Ca was significantly increased $24 \mathrm{~h}$ after the first MP pulse but returned to the baseline. values $24 \mathrm{~h}$ after the second pulse and decreased $\overrightarrow{\vec{\omega}}$ further after the last pulse. There were no significant $\stackrel{\omega}{\omega}$ changes found in the concentrations of PTH, 25$\mathrm{OHD}_{3}$, and $1 \alpha, 25\left(\mathrm{OH}_{2}\right) \mathrm{D}_{3}$. There was a tendency for PTH and $1 \alpha, 25\left(\mathrm{OH}_{2}\right) \mathrm{D}_{3}$ to increase afterct the first pulse, but $24 \mathrm{~h}$ after the second pulse these values returned to the starting values. It should be or noted that the starting values showed a slightlyo raised PTH concentration (normal values $<40 \mu \mathrm{g} / \mathrm{l}$ ). This has been noted before in RA. ${ }^{1}$ The concentra- $c s$ tions of $25-\mathrm{OHD}_{3}$ and $1 \alpha, 25\left(\mathrm{OH}_{2}\right) \mathrm{D}_{3}$ were in the $\frac{\mathbb{O}}{8}$ (lower) normal range. The starting values of $\mathrm{Ca} / \mathrm{Cr} \stackrel{\mathbb{D}}{ }$ and $\mathrm{OHProl} / \mathrm{Cr}$ excretion in the urine were slightly믐 above normal values.

In Fig. 2 the data for the urinary excretion of $\mathcal{G}_{a} \vec{\bullet}$ and OHProl are shown in more detail. Firstly, tipeo mean of the values of two $24 \mathrm{~h}$ periods befofetherapy are shown, then the data for the differento days during the MP pulse therapy, and finally the data for the mean of three $24 \mathrm{~h}$ periods after the MPO pulse therapy. During MP pulse therapy the $\mathrm{Ca} \frac{}{\mathrm{O}}$ excretion rose and the OHProl excretion tended to $\cong$ decrease. On the day of the first MP pulse the $\mathrm{Ca} \overrightarrow{\overrightarrow{\widehat{O}}}$ excretion was slightly decreased, followed by an 3 increase, peaking on the day of the second MP pulse? therapy. Later on $\mathrm{Ca}$ excretion decreased and? reached normal values immediately after pulse therapy. The OHProl excretion, however, tended to? stay decreased.

Table 1 Mean values and standard errors of the mean of some parameters of bone metabolism during MP pulse therapy

\begin{tabular}{|c|c|c|c|c|}
\hline & $\begin{array}{l}\text { Before first } \\
\text { pulse }\end{array}$ & $\begin{array}{l}24 h \text { after first } \\
\text { pulse }\end{array}$ & $\begin{array}{l}24 h \text { after second } \\
\text { pulse }\end{array}$ & $\begin{array}{l}\text { Three days after } \\
\text { third pulse }\end{array}$ \\
\hline \multicolumn{5}{|l|}{ Serum } \\
\hline $\mathrm{Ca}(\mathrm{mmol} / \mathrm{l})$ & $2 \cdot 38 \pm 0 \cdot 03$ & $2 \cdot 48 \pm 0.03^{*}$ & $2 \cdot 42 \pm 0 \cdot 03$ & $2 \cdot 29 \pm 0 \cdot 03^{*}$ \\
\hline PTH $(\mu \mathrm{g} / \mathrm{l})$ & $0.46 \pm 0.08$ & $0.52 \pm 0.08$ & $0.40 \pm 0.06$ & \\
\hline $25-\mathrm{OHD}_{3}(\mathrm{ng} / \mathrm{ml})$ & $26 \cdot 0 \pm 4 \cdot 3$ & $25 \cdot 0 \pm 3 \cdot 8$ & $22 \cdot 0 \pm 4 \cdot 3$ & \\
\hline \multirow[t]{2}{*}{$1 \alpha, 25\left(\mathrm{OH}_{2}\right) \mathrm{L}_{3}(\mathrm{pg} / \mathrm{ml})$} & $23 \cdot 8 \pm 2 \cdot 2$ & $26 \cdot 0 \pm 3 \cdot 5$ & $23 \cdot 9 \pm 2 \cdot 9$ & \\
\hline & Before pulse & During pulse & After pulse therapy & \\
\hline \multicolumn{5}{|l|}{ Urine } \\
\hline $\mathrm{Ca} / \mathrm{Cr}$ ratio & $0 \cdot 38 \pm 0 \cdot 05$ & $0.46 \pm 0.06^{*}$ & $0 \cdot 37 \pm 0 \cdot 03$ & \\
\hline OHProl/Cr ratio & $35 \cdot 8 \pm 4 \cdot 2$ & $28 \cdot 1 \pm 3 \cdot 6$ & $29 \cdot 7 \pm 3 \cdot 5$ & \\
\hline
\end{tabular}

*Significantly different from baseline values, $\mathrm{p}<0 \cdot 05$. 

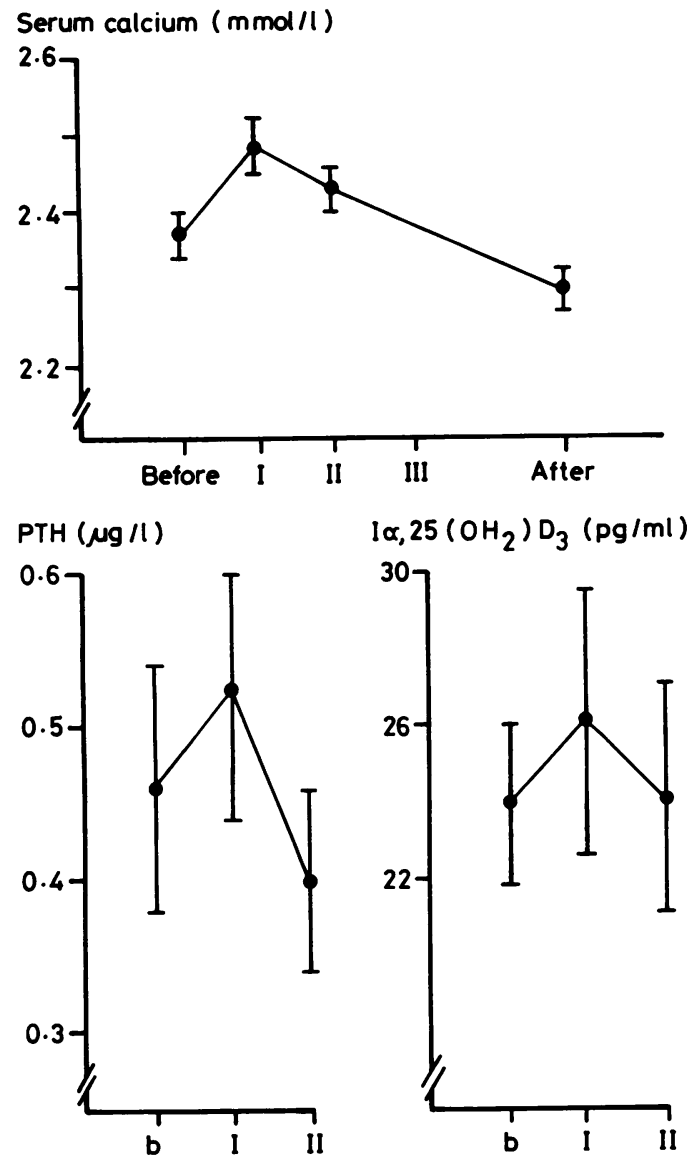

Fig. 1 Changes in serum calcium (mmol/l), parathyroid hormone $(P T H, \mu \mathrm{g} / \mathrm{l})$, and 1,25-dihydroxyvitamin $D\left(1 \alpha, 25\left(\mathrm{OH}_{2}\right) D_{3} . \mathrm{pg} / \mathrm{ml}\right)$ concentrations during treatment with methylprednisolone pulse therapy. I, II, and $I I I=$ first, second, and third pulse.

\section{Discussion}

In this short term study it is shown that changes found in bone metabolism during MP pulse therapy are only minor and transient. Already $24 \mathrm{~h}$ after the second pulse MP serum levels of $\mathrm{Ca}$, PTH, 25$\mathrm{OHD}_{3}$, and $1 \alpha, 25\left(\mathrm{OH}_{2}\right) \mathrm{D}_{3}$ have returned to the baseline values. Immediately after the last MP infusion the $\mathrm{Ca}$ excretion in the urine returned to the baseline value as well. The OHProl excretion stayed decreased. This probably indicates a decrease in bone resorption. It has been shown that urinary OHProl excretion also correlates with the activity of the RA disease. ${ }^{6}$ This correlation, however, probably reflects (juxta-articular) bone resorption and is
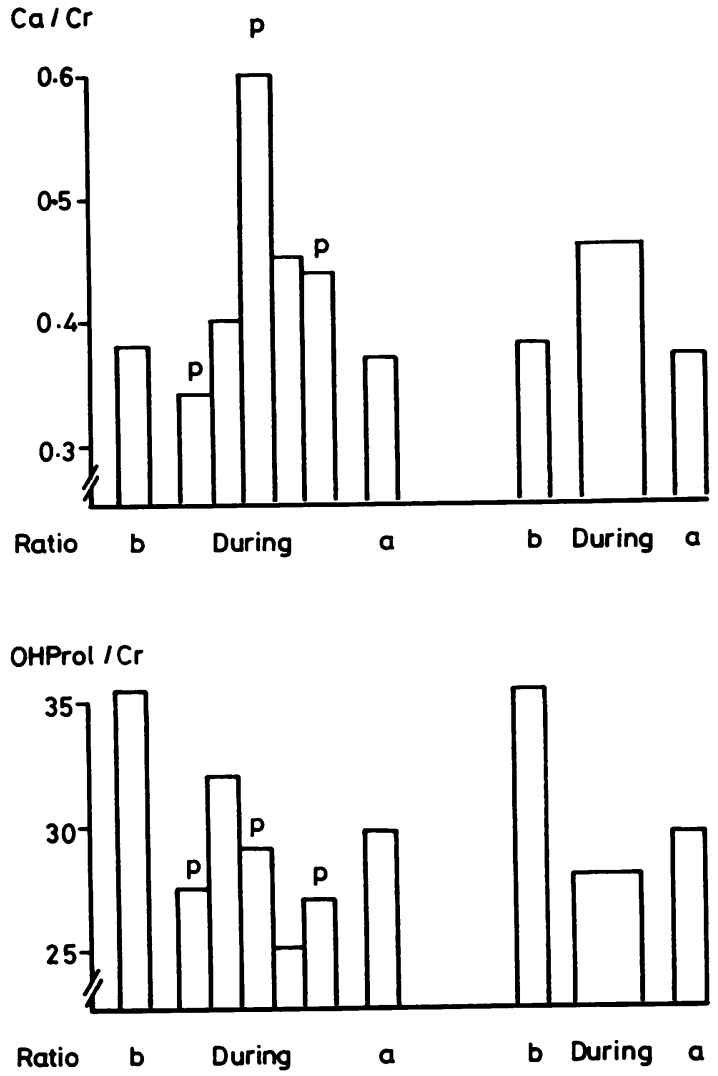

Fig. 2 Changes in urinary excretion of calcium ( $\mathrm{Ca}$ ) and hydroxyproline (OHProl), corrected for creatinine $(\mathrm{Cr})$ excretion. Left: $b=$ before therapy (mean of two times $24 \mathrm{~h}$ ); during = mean of the individual days, $p=M P$ pulse: on the first, third, and fifth day; $a=$ after (mean of three times $24 \mathrm{~h}$ ). On the right: during=mean of the five days during treatment.

only to a minor extent related to other factors such as turnover of the complement protein Clq. ${ }^{1}$ In our patients the activity of RA decreased markedly, and this may be reflected in the persistent decrease of the OHProl excretion.

The other slight changes found, however, are not easily explained. There is a lot of confusion regarding bone metabolism and corticosteroids. The following findings during CS therapy may be relevant: (a) CS hinder intestinal Ca absorption, probably by direct interference with intestinal calcium transport processes through inhibition of the mucosal calcium binding protein synthesis. ${ }^{7}(b) \mathrm{CS}$ increase urinary Ca excretion by decreasing renal tubular reabsorption of $\mathrm{Ca}^{8}{ }^{8}(\mathrm{c})$ In addition, CS inhibit the dif- 
ferentiation of osteoprogenitor cells to osteoblasts. ${ }^{7}$

These events lead to a decrease in serum Ca level, which stimulates PTH secretion. This rise in PTH subsequently leads to mobilisation of bone $\mathrm{Ca}$, by activating the osteoclasts, to a decrease in urinary $\mathrm{Ca}$ excretion, and to stimulation of the conversion of $25-\mathrm{OHD}_{3}$ to $1 \alpha, 25\left(\mathrm{OH}_{2}\right) \mathrm{D}_{3}$ by activation of the enzyme $1 \alpha$-hydroxylase. The increase in $1 \alpha$, $25\left(\mathrm{OH}_{2}\right) \mathrm{D}_{3}$ contributes to an increase in bone resorption, a decrease in urinary $\mathrm{Ca}$ excretion, and an increase in intestinal $\mathrm{Ca}$ absorption. Thus $\mathrm{CS}$ decrease bone formation and enhance bone resorption as well.

Although these mechanisms of CS induced osteopenia are well known during long term glucocorticoid excess there are only scanty data about the short term administration of massive amounts of CS. During intravenous administration of $200 \mathrm{mg}$ hydrocortisone over a period of four hours raised serum PTH levels were found, without detectable changes in serum Ca concentrations. ${ }^{9}$ When CS was given orally in high doses for at least one week a decreased fractional intestinal absorption of radioactive calcium was found; when CS were given over a shorter period of time only a small influence on intestinal radioactive calcium absorption was found, or none at all. ${ }^{10}$ Data on bone metabolism during MP pulse therapy have not been reported.

We did not measure intestinal calcium absorption but found, as expected, an increase in urinary $\mathrm{Ca}$ excretion. After $24 \mathrm{~h}$ we noted an increase in serum calcium instead of a decrease. It is possible that after the first MP pulse serum $\mathrm{Ca}$ initially fell very rapidly, giving rise to an increased $\mathrm{PTH}$ secretion and subsequent rise in $1 \alpha, 25\left(\mathrm{OH}_{2}\right) \mathrm{D}_{3}$ concentration. There was no increase in urinary $\mathrm{Ca}$ excretion on that first day, however, and it is rather unlikely that inhibition of calcium binding protein synthesis could influence serum Ca levels within a few hours. Another possibility is that massive dosages of CS lead to a rapid loss of the readily exchangeable bone calcium owing to osteolysis by osteocytes, ${ }^{11}$ with a subsequent increase in serum $\mathrm{Ca}$, followed by a gradual decrease as the readily exchangeable bone calcium stores are depleted. ${ }^{7}$ The slight increase in PTH and $1 \alpha, 25\left(\mathrm{OH}_{2}\right) \mathrm{D}_{3}$ in our study cannot be the result of stimulation by low serum $\mathrm{Ca}$ concentration but could be the result of a direct stimulation of PTH by CS, as shown by some $\mathrm{e}^{12}$ but disputed by others. ${ }^{13}$

It is clear from our limited data that the short term effects of high dose CS therapy differ from the known effects of long term CS therapy on bone metabolism. Perhaps the transient character may be $\Rightarrow$ caused by counter-regulatory effects, well known in $\stackrel{?}{?}$ the complicated processes of calcium homeostasis and bone metabolism. Further study and confirmation of our data are needed.

So far we have not noted any long term side $\stackrel{\mathbb{Q}}{\circ}$ effects such as osteonecrosis of the hip in our $\cong$ patients, but the follow up period is short.

In conclusion, bone resorption seems to decrease, but bone metabolism is not affected seriously and $\vec{\omega}$ only transiently by MP pulse therapy. This study adds to the evidence that the effects of CS on bone differ with duration and dosage of the therapy.

\section{References}

1 Sambrook P N, Ansell B M, Foster, S. et al. Bone turnover in carly rheumatoid arthritis. 1. Biochemical and kinetic indexes. Ann Rheum Dis 1985; 44: 575-9.

2 Bird H. The role of steroids in the treatment of arthritis. Ann $\mathrm{CS}$ Rheum Dis 1985; 44: 642-3.

3 Ncumann V. Hopkins R. Dixon J, Watkins A, Bird H, Wright $\frac{\bar{Q}}{\mathbb{D}}$ V. Combination therapy with pulsed methylprednisolone in 3 rhcumatoid arthritis. Ann Rheum Dis 1985: 44: 747-51

4 Williams I A. Baylis E M. Shipley M E. A double-blind $\frac{\mathbb{D}}{-}$ placcbo-controlled trial of methylprednisolone pulse therapy영 $\vec{C}$ active rheumatoid disease. Lancet 1982; ii: 237-9.

5 Bijlsma J W J. Duursma S A. Bosch R. Huber O. Lack To influence of the anabolic steroid nandrolondecanoate on bo metabolism. Acta Endocrinol 1982; 101: 140-3.

6 Mbuyl J M, Dequeker J. Teblick M. Merleveale M. Relevance of urinary excretion of alcian bluc glycosaminoglycan complexes and hydroxyproline to discase activity in rheumatoid arthritis. $J$ Rheumatol 1982; 9: 579-83.

7 Hahn Th J. Drug induced disorders of vitamin D and mineral $\vec{F}$ metabolism. Clin Endocrinol Metab 1980; 9: 107-29.

8 Suzuki Y, Ichikawa Y, Saito E, Homma M. Importance of increased urinary calcium excretion in the development of secondary hyperparathyroidism of patients under glucocorticoid? therapy. Metabolism 1983; 32: 151-6.

9 Fucik R F, Kukreja S C, Hargis G K, Bowser E N, Henderson W J, Williams G A. Effect of glucocorticoids on function of the $\bar{\sigma}$ parathyroid glands in man. J Clin Endocrinol Metab 1975; 40: 152-5.

10 Zerwekh J E, Pak G Y C, Kaplan R A, et al. Pathogenetic role of 1,25-dihydroxyvitamin $\mathrm{D}$ in sarcoidosis and absorptive hypercalciuria: different response to prednisolone therapy.음 J Clin Endocrinol Metab 1980; 51: 381-6.

11 Bèlanger L F. Osteocytic osteolysis. Calcif Tissue Res 1969; 4: $\frac{D}{O}$ 1-12.

$12 \mathrm{Au}$ W Y W. Cortisol stimulation of parathyroid hormone secretion by rat parathyroid glands in organ culture. Sciences

13 Braun J J, Juttmann J R, Visser T J, Birkenhäger J C. Shortterm effect of prednisone on serum 1,25-dihydroxyvitamin $\mathrm{D}$ inW normal individuals and in hyper- and hypo-parathyroidism. Cling Endocrinol (Oxf) 1982; 17: 21-8. 